DOI: $10.34185 / 1991-7848.2019 .01 .05$

УДК 669.018.73:536

А.М. Гришин, А.А. Надточий, И.С. Щеглова

\title{
ТЕРМОДИНАМИЧЕСКОЕ МОДЕЛИРОВАНИЕ УГЛЕРОДОТЕРМИЧЕСКОГО ВОССТАНОВЛЕНИЯ ХРОМИТА ЖЕЛЕЗА
}

\begin{abstract}
Сложность термодинамического анализа такого процесса восстановления хромита железа заключается в его многовариантности. В зависимости от условий реализации процесса конечные продукты восстановления могут иметь различный фазовый $u$ химический состав. Целью данной работы является термодинамический анализ закономерностей восстановления хромита железа углеродом при температурах, исключающих появление жидких фаз. В работе выполнен термодинамический анализ основных реакций в системах $\mathrm{Cr}-\mathrm{O}-\mathrm{C}$ и $\mathrm{Cr}-\mathrm{Fe}-\mathrm{O}-\mathrm{C}$, протекающих с образованием металлической и карбидной фаз различного состава. Определены температуры начала восстановления хромита $\mathrm{Cr}_{2} \mathrm{FeO}_{4}$ в условиях образования металлического продукта $u$ карбидов при использовании в качестве восстановителей твердого углерода, карбида железа и карбида хрома. Подтверждена гипотеза о последовательности восстановления железа и хрома из хромита при температурах, исключающих появление жидких фаз. Предложена вероятная схема формирования металлической и карбидной фаз. Выполнено термодинамическое моделирование углеродотермического восстановления хромита железа при различном соотношении $\mathrm{O} / \mathrm{C}$, а также при введении в систему дополнительно $\mathrm{Fe}_{3} \mathrm{O}_{4}$ u $\mathrm{Cr}_{2} \mathrm{O}_{3}$.
\end{abstract}

Ключевые слова: хромит железа, восстановление, карбиды, углерод, термодинамическое моделирование.

\section{Постановка проблемы}

Физико-химические особенности восстановления хромита железа были предметом многих исследований [1-5], однако до настоящего времени нет единого представления как о механизме процесса, так и его физико-химических закономерностях. В большей степени это касается твердофазного восстановления, целью которого является получение губчатых лигатур. Сложность термодинамического анализа такого процесса заключается в его многовариантности. В зависимости от условий реализации процесса конечные продукты восстановления могут иметь различный фазовый и химический состав.

Химический и минералогический состав хромовой руды весьма разнообразен, что предопределяет сложную и многостадийную технологию ее переработки, которая сопровождается различными физико-химическими превращениями.

Хромит железа $-\mathrm{Cr}_{2} \mathrm{FeO}_{4}$ является основным хромсодержащим минералом хромовой руды. Хромит железа имеет сложную кристаллографическую структуру и не менее сложную структуру химических связей внутри молекулы. В литературе нет

(c) Гришин А.М., Надточий А.А., Щеглова И.С. , 2019 
достоверных данных о закономерностях изменения кристаллографических характеристик шпинели в процессе ее восстановления, что также усложняет термодинамический анализ восстановления $\mathrm{Cr}_{2} \mathrm{FeO}_{4}$.

\section{Анализ последних исследований}

По литературным сведениям и результатам наших исследований $[1,6-8]$ углеродотермическое восстановление хромита железа осуществляется по двухзвенному механизму А.А. Байкова. Восстановление с участием газовой фазы в значительной мере зависит также и от газопроницаемости кусков [9]. Для мелкокристаллических руд, представляющих собой зерна хромита, вкрапленные в рыхлую вмещающую породу, восстановление протекает по всему объему. Аналогичные результаты также были получены [10]. Многие исследователи придерживаются мнения о последовательном восстановлении железа и хрома из хромита $\mathrm{Cr}_{2} \mathrm{FeO}_{4}$. Проведенный нами термодинамический анализ углеродотермического и комплексного восстановления хромовой руды[11], подтверждают данную гипотезу.

\section{Цель исследования}

Целью данной работы является термодинамический анализ закономерностей восстановления хромита железа углеродом при температурах, исключающих появление жидких фаз.

\section{Основной материал исследования}

При восстановлении $\mathrm{Cr}_{2} \mathrm{FeO}_{4}$ углеродом первым восстанавливается железо по реакции $\mathrm{Cr}_{2} \mathrm{FeO}_{4}+\mathrm{CO}=\mathrm{Fe}+\mathrm{Cr}_{2} \mathrm{O}_{3}+\mathrm{CO}_{2}$. Расчет равновесной концентрации $\mathrm{CO}_{2}$ показал изменения от $0,56 \%$ при $900^{\circ} \mathrm{C}$ до $\sim 1,5 \%$ при $1350^{\circ} \mathrm{C}$. Газовая фаза более чем на порядок обедняется диоксидом углерода по сравнению с реакцией $\mathrm{FeO}+\mathrm{CO}=\mathrm{Fe}+\mathrm{CO}_{2}$.

Этот сдвиг сохраняется и в случае образования карбида железа $\mathrm{Cr}_{2} \mathrm{FeO}_{4}+5 / 3 \mathrm{CO}=$ $1 / 3 \mathrm{Fe}_{3} \mathrm{C}+\mathrm{Cr}_{2} \mathrm{O}_{3}+4 / 3 \mathrm{CO}_{2}$. Для указанных выше температур равновесный \% $\mathrm{CO}_{2}$ составляет 0,88 и $\sim 0,6 \%$, соответственно.

Полное восстановление хромита железа можно представить реакцией $1 / 4 \mathrm{Cr}_{2} \mathrm{FeO}_{4}+\mathrm{CO}=1 / 4 \mathrm{Fe}+1 / 2 \mathrm{Cr}+\mathrm{CO}_{2}$, при этом равновесная концентрация диоксида углерода при тех же температурах снижается до $\sim 0,02$ и 0,20\%. В случае образования карбида хрома $\mathrm{Cr}_{3} \mathrm{C}_{2}$ состав газовой фазы по $\mathrm{CO}_{2}$ составляет $\sim 0,27 \%$ при $900^{\circ} \mathrm{C}$ и $0,32 \%$ при $1350^{\circ} \mathrm{C}$. Наконец, в случае образования двух карбидов $\mathrm{Cr}_{3} \mathrm{C}_{2}$ и $\mathrm{Fe}_{3} \mathrm{C}$ равновесная концентрация $\mathrm{CO}_{2}-0,32$ и $0,28 \%$ при 900 и $1350^{\circ} \mathrm{C}$, соответственно. Полученные результаты расчета равновесного состава газа для интервала температур 1173-1673 представлены на рисунке 1. Анализ полученных данных свидетельствует о достаточно близкой восстановимости хрома и железа, что создает предпосылки для параллельного восстановления железа и хрома из сложного оксидного соединения. 
Вероятнее всего это может иметь место на завершающей стадии восстановления железа.

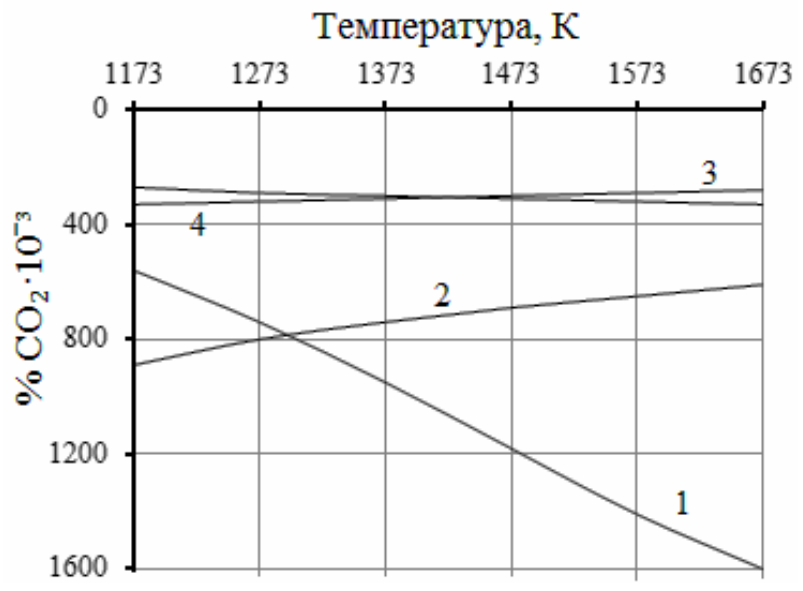

Рисунок 1 - Равновесный состав газовой фазы для реакций восстановления хромита железа:

$1-\mathrm{Cr}_{2} \mathrm{FeO}_{4}+\mathrm{CO}=\mathrm{Fe}+\mathrm{Cr}_{2} \mathrm{O}_{3}+\mathrm{CO}_{2}$;

$2-\mathrm{Cr}_{2} \mathrm{FeO}_{4}+5 / 3 \mathrm{CO}=1 / 3 \mathrm{Fe}_{3} \mathrm{C}+\mathrm{Cr}_{2} \mathrm{O}_{3}+4 / 3 \mathrm{CO}_{2}$;

$3-1 / 4 \mathrm{Cr}_{2} \mathrm{FeO}_{4}+11 / 6 \mathrm{CO}=1 / 12 \mathrm{Fe}_{3} \mathrm{C}+1 / 6 \mathrm{Cr}_{3} \mathrm{C}_{2}+17 / 12 \mathrm{CO}_{2}$;

$4-1 / 4 \mathrm{Cr}_{2} \mathrm{FeO}_{4}+5 / 3 \mathrm{CO}=1 / 4 \mathrm{Fe}+1 / 6 \mathrm{Cr}_{3} \mathrm{C}_{2}+4 / 3 \mathrm{CO}_{2}$

Сделанный вывод подтверждается температурами начала восстановления $\left(\mathrm{T}_{\mathrm{H}}\right)$ $\mathrm{Cr}_{2} \mathrm{FeO}_{4}$ углеродом. Расчет $\mathrm{T}_{\text {н }}$ можно осуществить с достаточной точностью при малых концентрациях $\mathrm{CO}_{2}$ в газовой фазе на основе соотношения $T_{н}=\Delta H^{0} /\left(\Delta S^{0}-R \cdot \ln K\right)$. При необходимости для различных значений $\alpha=P_{\mathrm{CO}}+P_{\mathrm{CO}_{2}}$ расчет может быть выполнен по методике, описанной в [12].

В отсутствие растворов для реакций углеродотермического восстановления хромита железа $K=P_{\text {со }}$, где $P_{\text {со }}$ в свою очередь, практически равно общему давлению углеродсодержащих газов $\alpha$. При условии $\alpha=P_{\mathrm{CO}}+P_{\mathrm{CO}_{2}}=1$ для различных реакций в рассматриваемой системе $\mathrm{T}_{\text {н }}$ представлены в таблице 1.

Таблица 1

Температуры начала восстановления $\mathrm{Cr}_{2} \mathrm{FeO}_{4}$ углеродом при $\alpha=1$

\begin{tabular}{|l|l|}
\hline Уравнение реакции & $\mathrm{T}_{\mathrm{H}}{ }^{0} \mathrm{C}$ \\
\hline $1 / 2 \mathrm{Cr}_{2} \mathrm{FeO}_{4}+1 / 2 \mathrm{C}=1 / 2 \mathrm{Fe}+1 / 2 \mathrm{Cr}_{2} \mathrm{O}_{3}+1 / 2 \mathrm{CO}$ & 1306 \\
\hline $1 / 2 \mathrm{Cr}_{2} \mathrm{FeO}_{4}+4 / 6 \mathrm{C}=1 / 6 \mathrm{Fe}_{3} \mathrm{C}+1 / 2 \mathrm{Cr}_{2} \mathrm{O}_{3}+1 / 2 \mathrm{CO}$ & 1302 \\
\hline $1 / 2 \mathrm{Cr}_{2} \mathrm{FeO}_{4}+8 / 3 \mathrm{C}=1 / 2 \mathrm{Fe}+1 / 3 \mathrm{Cr}_{3} \mathrm{C}_{2}+2 \mathrm{CO}$ & 1372 \\
\hline $1 / 2 \mathrm{Cr}_{2} \mathrm{FeO}_{4}+17 / 6 \mathrm{C}=1 / 6 \mathrm{Fe}_{3} \mathrm{C}+1 / 3 \mathrm{Cr}_{3} \mathrm{C}_{2}+2 \mathrm{CO}$ & 1371 \\
\hline $1 / 2 \mathrm{Cr}_{2} \mathrm{FeO}_{4}+17 / 7 \mathrm{C}=1 / 2 \mathrm{Fe}+1 / 7 \mathrm{Cr}_{7} \mathrm{C}_{3}+2 \mathrm{CO}$ & 1387 \\
\hline $1 / 2 \mathrm{Cr}_{2} \mathrm{FeO}_{4}+109 / 42 \mathrm{C}=1 / 6 \mathrm{Fe}_{3} \mathrm{C}+1 / 7 \mathrm{Cr}_{7} \mathrm{C}_{3}+2 \mathrm{CO}$ & 1386 \\
\hline $1 / 2 \mathrm{Cr}_{2} \mathrm{FeO}_{4}+1 / 2 \mathrm{Fe}_{3} \mathrm{C}=2 \mathrm{Fe}+1 / 2 \mathrm{Cr}_{2} \mathrm{O}_{3}+1 / 2 \mathrm{CO}$ & 1322 \\
\hline $1 / 2 \mathrm{Cr}_{2} \mathrm{FeO}_{4}+8 / 3 \mathrm{Fe}_{3} \mathrm{C}=17 / 2 \mathrm{Fe}+1 / 3 \mathrm{Cr}_{3} \mathrm{C}_{2}+2 \mathrm{CO}$ & 1398 \\
\hline $1 / 2 \mathrm{Cr}_{2} \mathrm{FeO}_{4}+17 / 7 \mathrm{Fe}_{3} \mathrm{C}=109 / 14 \mathrm{Fe}+1 / 7 \mathrm{Cr}_{7} \mathrm{C}_{3}+2 \mathrm{CO}$ & 1412 \\
\hline $1 / 2 \mathrm{Cr}_{2} \mathrm{FeO}_{4}+2 \mathrm{Fe}_{3} \mathrm{C}=13 / 2 \mathrm{Fe}+\mathrm{Cr}+2 \mathrm{CO}$ & 1502 \\
\hline $1 / 2 \mathrm{Cr}_{2} \mathrm{FeO}_{4}+34 / 10 \mathrm{Cr}_{3} \mathrm{C}_{2}=1 / 2 \mathrm{Fe}+16 / 10 \mathrm{Cr}_{7} \mathrm{C}_{3}+2 \mathrm{CO}$ & 1548 \\
\hline
\end{tabular}


Каждую из приведенных реакций можно представить как совокупность реакций косвенного восстановления $\mathrm{Cr}_{2} \mathrm{FeO}_{4}$ и газификации $\mathrm{C}_{\text {тв }}$ (или карбидов) углекислым газом $\mathrm{C}+\mathrm{CO}_{2}=2 \mathrm{CO}$, для которой равновесный состав газовой фазы рассчитывается по известному уравнению \%СО $=50 \cdot K_{10} / P \cdot\left[\sqrt{1+4 \cdot P / K_{10}}-1\right]$.

Результаты расчета представлены на рисунке 2. Полученные данные позволяют проанализировать фазовые превращения при восстановлении $\mathrm{Cr}_{2} \mathrm{FeO}_{4}$ углеродом с термодинамической точки зрения.

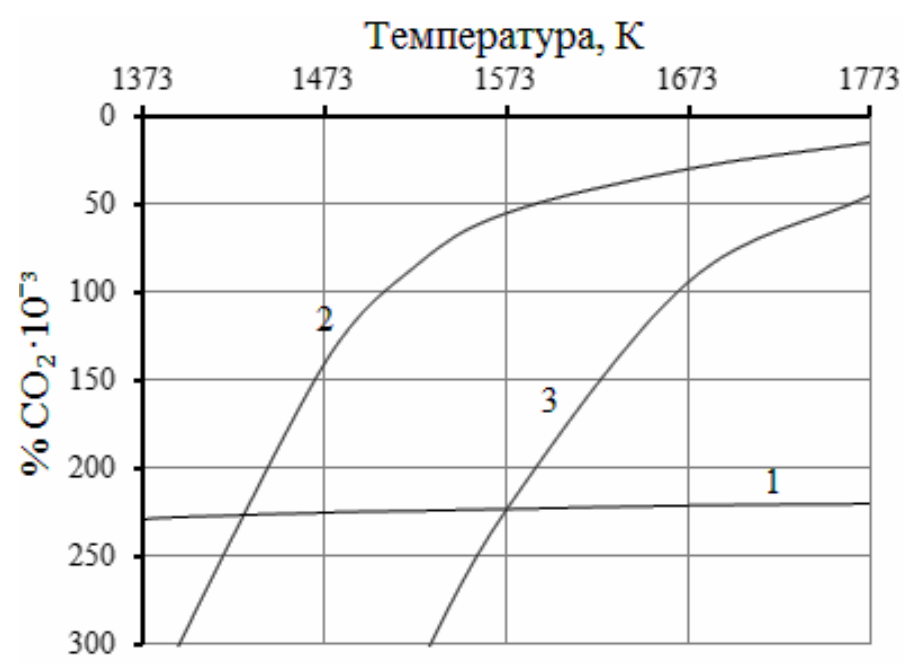

Рисунок 2 - Области устойчивого существования различных фаз при восстановлении $\mathrm{Cr}_{2} \mathrm{O}_{3}$ карбидами железа и хрома:

$$
1-1 / 3 \mathrm{Cr}_{2} \mathrm{O}_{3}+17 / 9 \mathrm{CO}=2 / 9 \mathrm{Cr}_{3} \mathrm{C}_{2}+13 / 9 \mathrm{CO}_{2} \text {; }
$$$$
2-\mathrm{Fe}_{3} \mathrm{C}+\mathrm{CO}_{2}=3 \mathrm{Fe}+2 \mathrm{CO} ; 3-7 / 5 \mathrm{Cr}_{3} \mathrm{C}_{2}+\mathrm{CO}_{2}=3 / 5 \mathrm{Cr}_{7} \mathrm{C}_{3}+2 \mathrm{CO}
$$

Наряду с твердым углеродом в роли восстановителя могут выступать карбиды. Например, для реакции восстановления оксида хрома карбидом железа $1 / 2 \mathrm{Cr}_{2} \mathrm{FeO}_{4}+$ $8 / 3 \mathrm{Fe}_{3} \mathrm{C}=17 / 2 \mathrm{Fe}+1 / 3 \mathrm{Cr}_{3} \mathrm{C}_{2}+2 \mathrm{CO}$ температура начала восстановления при общем давлении 1 составляет 1398K. В случае восстановления оксида хрома высшим карбидом хрома $1 / 2 \mathrm{Cr}_{2} \mathrm{FeO}_{4}+17 / 7 \mathrm{Cr}_{3} \mathrm{C}_{2}=109 / 14 \mathrm{Fe}+1 / 7 \mathrm{Cr}_{7} \mathrm{C}_{3}+2 \mathrm{CO}$ высокая химическая прочность $\mathrm{Cr}_{3} \mathrm{C}_{2}$ обуславливает значительный рост $\mathrm{T}_{\text {н }}$ до $\sim 1548 \mathrm{~K}$. Полученные $\mathrm{T}_{\text {н }}$ близки к результатам, полученным авторами [13].

Однако в указанной выше схеме не учтена возможность образования сложных карбидов за счет изоморфного замещения атомов хрома в решетке карбидов хрома атомами железа, что, вероятно, изменит термодинамику процесса. Следует подчеркнуть, что вовлечение карбидов в восстановление оксидных фаз создает возможность обезуглероживания получаемой железохромистой лигатуры.

Таким образом, $\mathrm{T}_{\text {н }}$ и равновесный состав газовой фазы служат подтверждением последовательности восстановления железа и хрома. Это справедливо при изотермическом и неизотермическом режимах процесса. Равновесный состав газовой фазы и относительно невысокие температуры при восстановлении оксидов железа будут термодинамически запрещать восстановление хрома. Однако при 
восстановлении хромита железа четкая последовательность превращений теряется, что обусловлено сложностью химических связей в молекуле $\mathrm{Cr}_{2} \mathrm{FeO}_{4}$. Полученные термодинамические данные свидетельствуют о весьма близкой вероятности получения на первом этапе, как чистого железа, так и $\mathrm{Fe}_{3} \mathrm{C}$. В пользу карбида свидетельствует наличие в шихте свободного углерода на момент появления железа. Вместе с тем, $\mathrm{C}_{\text {тв }}$ и $\mathrm{Fe}_{3} \mathrm{C}$ как восстановители по отношению к различным оксидам термодинамически весьма близки. Исходя из сказанного можно предположить, что образовавшееся $\mathrm{Fe}_{\text {мет }}$ проходит процесс науглероживания, достигая предельного значения, превращается в карбид $\mathrm{Fe}_{3} \mathrm{C}$ по реакции: $\mathrm{Fe}_{\text {нас. } \mathrm{C}}+\mathrm{C}=\mathrm{Fe}_{3} \mathrm{C}$, которая термодинамически разрешена выше 1063K. Таким образом, на начальном этапе восстановления в анализируемой системе, кроме исходных компонентов шихты, могут образоваться $\mathrm{Fe}$ и $\mathrm{Fe}_{3} \mathrm{C}$. Образующийся цементит может участвовать в процессе восстановления практически равноправно со свободным углеродом, однако строго термодинамически в области умеренных температур более предпочтителен $\mathrm{C}_{\text {тв. }}$

При достижении условий начала восстановления хрома в системе, кроме частично восстановленного хромита и углерода, присутствуют $\mathrm{Fe}_{\text {нас.с }}$ и/или $\mathrm{Fe}_{3} \mathrm{C}$. Процесс может развиваться по трем гипотетически возможным схемам:

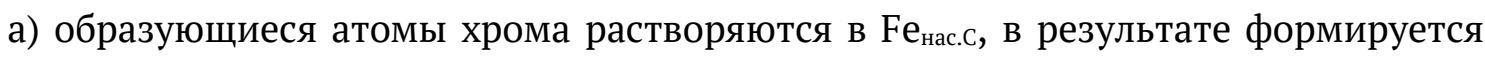
совместный металлический раствор;

б) атомы хрома по механизму замещения легируют цементит, образуя фазу $\mathrm{M}_{3} \mathrm{C}$;

в) восстановленные атомы хрома образуют карбиды в последовательности $\mathrm{Cr}_{23} \mathrm{C}_{6} \rightarrow \mathrm{Cr}_{7} \mathrm{C}_{3} \rightarrow \mathrm{Cr}_{3} \mathrm{C}_{2}$, которые могут растворять атомы железа (на разных стадиях), либо взаимодействовать с карбидом железа по более сложной схеме.

Не может быть исключен и вариант параллельной реализации указанных схем. Хром обладает большим сродством к углероду, чем железо, т.е. является более сильным карбидообразующим элементом и вероятнее, что на базе именно карбида хрома формируется карбид $(\mathrm{Cr}, \mathrm{Fe})_{\mathrm{n}} \mathrm{C}_{\mathrm{m}}$. Однако, при наличии в системе карбида железа атомы хрома могут легировать его, образуя карбид (Fe, Cг) ${ }_{3} \mathrm{C}$. До настоящего времени нет единого мнения о растворимости хрома в цементите. По мнению $[14,15]$ эта величина составляет 20 масс. \%. Авторами [16] отмечается, что в цементите может растворяться до 18 \% (ат.) Cr, что соответствует 21,18 масс. \%. Нет однозначного мнения о существовании карбида $\mathrm{Fe}_{7} \mathrm{C}_{3}$.

Не следует исключить возможность довосстановления оставшегося железа параллельно с восстановлением хрома, т.е. наложение этих процессов. В этом случае при наличии в системе $\mathrm{C}_{\text {тв }}$ запускается процесс формирования сложного карбида через образование $\mathrm{Cr}_{23} \mathrm{C}_{6}$ до $(\mathrm{Cr}, \mathrm{Fe})_{23} \mathrm{C}_{6}$. Учитывая, что скорость диффузии углерода выше, чем хрома, $\mathrm{Cr}_{23} \mathrm{C}_{6}$ превращается в $\mathrm{Cr}_{7} \mathrm{C}_{3}$ и в высший карбид при условии достаточного количества углерода в системе. Таким образом, углерод расходуется на восстановление и на карбидообразование. Термодинамически более предпочтителен процесс карбидообразования по реакции: $\mathrm{Cr}_{23} \mathrm{C}_{6}+\mathrm{C}=\mathrm{Cr}_{7} \mathrm{C}_{3}$ и далее до высшего 
карбида. Весьма сложно предположить, как эти превращения будут коррелироваться с формированием сложного карбида. Вероятность какого-либо варианта может быть оценена только при наличии термохимических данных для сложных карбидов.

Дефицит углерода при восстановлении $\mathrm{Cr}_{2} \mathrm{FeO}_{4}$ меняет термодинамическую картину процесса. На определенной стадии процесса, когда углерод полностью израсходован, функции твердого восстановителя переходят к карбиду $(\mathrm{Cr}, \mathrm{Fe})_{3} \mathrm{C}_{2}$. Вероятно, газификация такого карбида на начальном этапе связана с потерей углерода, связанного с железом, т.к. хром имеет более сильное сродство к углероду. Об этом косвенно свидетельствуют $\mathrm{T}_{\mathrm{H}}$ и равновесный состав газовой фазы для углекислотной газификации $\mathrm{Fe}_{3} \mathrm{C}$ и $\mathrm{Cr}_{3} \mathrm{C}_{2}$. Потеря карбидом углерода и части железа приводит к перестройке его решетки и трансформации в $\left(\mathrm{Cr}_{1-\mathrm{x}}, \mathrm{Fe}_{\mathrm{x}}\right)_{7} \mathrm{C}_{3}$, который имеет большее соотношение $\mathrm{Cr} / \mathrm{Fe}$. Для тригонального карбида, вероятно, газификация также сопровождается потерей железа и перестройкой его в $\left(\mathrm{Cr}_{1-\mathrm{y}}, \mathrm{Fe}_{\mathrm{y}}\right)_{23} \mathrm{C}_{6}$ с дальнейшим повышением $\mathrm{Cr} / \mathrm{Fe}$. На завершающей стадии $\left(\mathrm{Cr}_{1-\mathrm{y}}, \mathrm{Fe}_{\mathrm{y}}\right)_{23} \mathrm{C}_{6}$ трансформируется в раствор /Cr-Fe/, насыщенный углеродом. Не следует исключать вероятность формирования тройных карбидов, например, за счет атомов $\mathrm{Ni}$, образовавшихся в процессе восстановления сопутствующих компонентов шихты. Таким образом, приведенная физико-химическая модель трансформации карбида в ходе углеродотермического восстановления хромита железа является звеном газификации твердого восстановителя. Второе звено - восстановление $\mathrm{Cr}_{2} \mathrm{FeO}_{4}$ сложным карбидом, которое можно условно представить схемой

$$
\mathrm{Cr}_{2} \mathrm{FeO}_{4}+(\mathrm{Cr}, \mathrm{Fe})_{3} \mathrm{C}_{2}=/ \mathrm{Cr}-\mathrm{Fe} / \text { нас.С }+\mathrm{CO}+\mathrm{CO}_{2} \text {. }
$$

Организация углеродотермического восстановления хромита железа возможно при различных соотношениях $\mathrm{O} / \mathrm{C}=4 \ldots 0,7$. Результаты термодинамического моделирования некоторых возможных вариантов процесса представлены на рисунке 3.

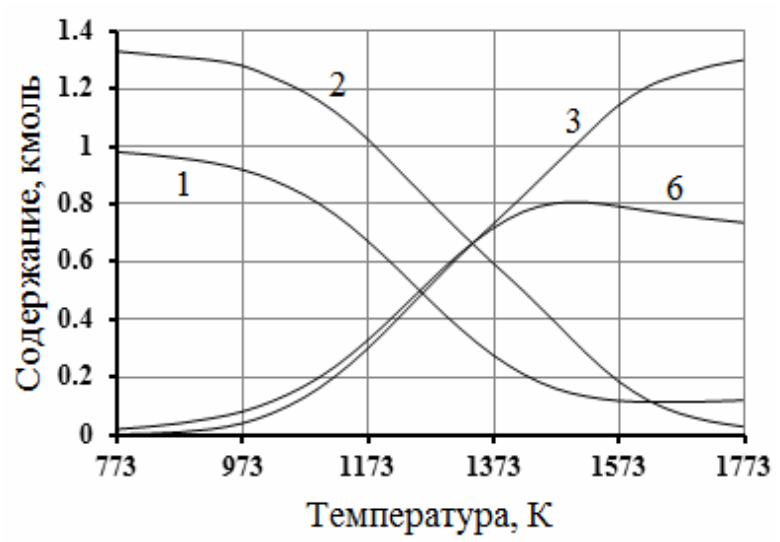

a)

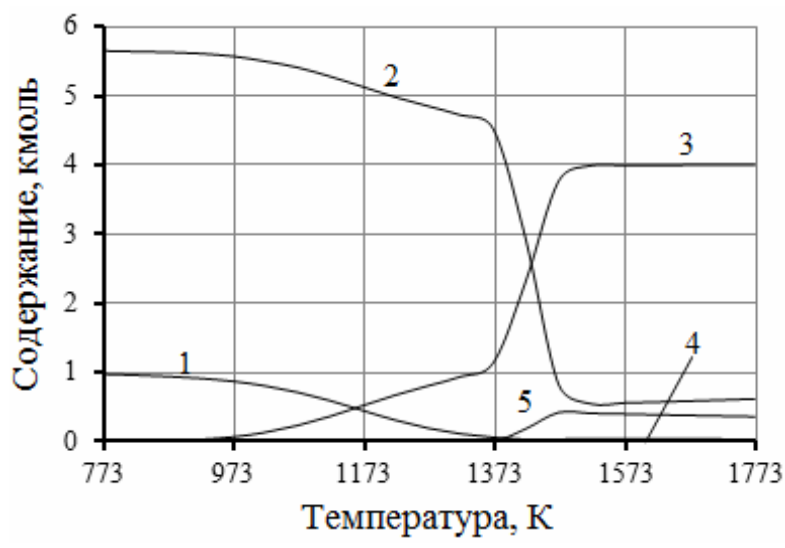

б)

Рисунок 3 - Термодинамическое моделирование углеродотермического восстановления $\mathrm{Cr}_{2} \mathrm{FeO}_{4}$ в системах: $\mathrm{a}-\left(\mathrm{Cr}_{2} \mathrm{FeO}_{4}+4 / 3 \mathrm{C}\right) ; 6-\left(\mathrm{Cr}_{2} \mathrm{FeO}_{4}+17 / 3 \mathrm{C}\right): 1-\mathrm{Cr}_{2} \mathrm{FeO}_{4} ; 2-\mathrm{C} ; 3-\mathrm{CO}$; $4-\mathrm{Fe}_{3} \mathrm{C} ; 5-\mathrm{Cr}_{3} \mathrm{C}_{2} ; 6-\mathrm{Cr}_{2} \mathrm{O}_{3}$ 
Таким образом, именно соотношение O/C при постоянстве $\mathrm{Cr} / \mathrm{Fe}$ и температуры главным образом определяет фазовый состав продукта. Расчетные данные значений энергий Гиббса для реакций восстановления с соотношением $\mathrm{O} / \mathrm{C}=4 . . .3$ показали практическу равную термодинамическую вероятность их протекания до температуры 1393K, т.е. до температуры начала восстановления хрома. При повышении температуры более вероятны реакции с соотношением $\mathrm{O} / \mathrm{C}=1 . . .0,7$, также с близкими значениями $\Delta \mathrm{G}^{0}$. Таким образом, могут быть определены термодинамические условия углеродотермического восстановления $\mathrm{Cr}_{2} \mathrm{FeO}_{4}$ с целью получения лигатуры с низким содержанием углерода.

По результатам исследований комплексного восстановления окалины высокохромистой стали, выполненных $[17,18]$, губчатую лигатуру с C $\square 0,15 \%$ получали при $\mathrm{O} / \mathrm{C} \geqslant 1,95$ и температуре $1573 \mathrm{~K}$. Введение в шихту $\mathrm{NiO}$ для получения $\mathrm{Fe}-\mathrm{Cr}-\mathrm{Ni}$ лигатуры изменяет соотношение О/C 2,2...2,3 при том же содержании углерода. Исследования касались получения лигатуры с содержанием хрома до 20\%. Повышение содержания хрома в лигатуре требует уменьшение соотношения O/C, что приводит к образованию карбидов из-за высокого сродства хрома к углероду. Однако такие исследования о влиянии соотношения $\mathrm{Cr} / \mathrm{Fe}$ в шихте на уровень углерода в конечном продукте не проводились. При углеродотермическом восстановлении остаточное содержание углерода в лигатуре при одинаковых условиях, вероятно, будет выше, чем при комплексном восстановлении, однако это требует дополнительной проверки.

Вносимый в систему углерод расходуется на взаимодействие с кислородом, образование карбидов, а также на формирование углеродного потенциала равновесной газовой фазы. Повышение углерода в системе приводит к увеличению доли карбидов и изменению их морфологии. Формальное термодинамическое моделирование показывает, что при $\mathrm{O} / \mathrm{C} \geqslant 3$ практически весь углерод расходуется на восстановление железа и превращение его в карбид $\mathrm{Fe}_{3} \mathrm{C}$. Повышение углерода в шихте и температуры запускает реакции восстановление хрома и формирование сложных карбидов. По результатам авторов [17, 18], а также нашим расчетам, восстановление хромита до чистых металлов (раствора $/ \mathrm{Fe}-\mathrm{Cr} /$ нас.с) возможно при определенном значении температуры, O/C и $\mathrm{Cr} / \mathrm{Fe}$.

При соотношении $\mathrm{O} / \mathrm{C}=3$ (рис. 3, а) содержания $\mathrm{Cr}_{2} \mathrm{FeO}_{4}$ (кр.1) и $\mathrm{Cr}_{2} \mathrm{O}_{3}$ (кр.6) изменяются в противоположном направлении. Повышение температуры > 1473K приводит к снижению содержания оксида хрома, равно как и углерода, что свидетельствует о предпочтительности восстановления хрома из его оксида перед восстановлением хромита. При соотношении $\mathrm{O} / \mathrm{C}=0,7$ (рис. 3, б) значительно меняется картина процесса. При повышении температуры более $1373 \mathrm{~K}$ наблюдается возрастание карбида $\mathrm{Cr}_{3} \mathrm{C}_{2}$ при резком снижении углерода. При этой же температуре возрастает содержание карбида $\mathrm{Fe}_{3} \mathrm{C}$, проходя при $1520 \mathrm{~K}$ через максимум, хотя и остается на очень низком уровне ( 0,04 кмоль). Дальнейшее повышение температуры не приводит к какому-либо изменению компонентов, что вероятно связано с 
переходом к иной схеме протекания процесса. Дальнейшее снижение О/C кардинально не меняет термодинамическую картину процесса, изменяя только количественные показатели.

Введение в исходную шихту дополнительно $\mathrm{Cr}_{2} \mathrm{O}_{3}$ либо $\mathrm{Fe}_{3} \mathrm{O}_{4}$, т.е. изменение соотношения $\mathrm{Cr} / \mathrm{Fe}$, меняет термодинамическую картину. Введение в шихту дополнительного $\mathrm{Cr}_{2} \mathrm{O}_{3}$ показывают весьма близкую картину $\mathrm{k}$ процессу восстановления хромита железа без дополнительного $\mathrm{Cr}_{2} \mathrm{O}_{3}$ (рис. 3, б), однако максимальное количество карбида хрома $\mathrm{Cr}_{3} \mathrm{C}_{2}$ достигается при меньшей температуре, что вероятно связано с наличием в системе свободного оксида хрома $\mathrm{Cr}_{2} \mathrm{O}_{3}$. Увеличение количества карбида $\mathrm{Cr}_{3} \mathrm{C}_{2}$ коррелируется с расходованием углерода и возрастанием CO. Следует также отметить, что восстановление Fe в значительной степени реализуется на начальной стадии, тогда как $\mathrm{Cr}$ появляется при более высоких температурах. Таким образом, подтверждается гипотеза о раздельном восстановлении железа и хрома.

Термодинамическое моделирование при введении в шихту дополнительного количества $\mathrm{Fe}_{3} \mathrm{O}_{4}$ показывает схожую картину к процессу с соотношением $\mathrm{O} / \mathrm{C}=0,7$, но имеются некоторые отличия. Главным образом это касается характера расходования углерода, восстановления $\mathrm{Cr}_{2} \mathrm{O}_{3}$ и температурных условий формирования карбидной фазы, а также более четкого разделения восстановления железа и хрома. Однако наблюдается определенное наложение одновременного восстановления железа и хрома при более высоких температурах.

\section{Выводы}

1. Получила подтверждение гипотеза о последовательности углеродотермического восстановления железа и хрома из хромита железа, как при участии углерода, так и при восстановлении карбидами.

2. Определены температуры начала восстановления хромита $\mathrm{Cr}_{2} \mathrm{FeO}_{4}$ в условиях образования металлического продукта и карбидов при использовании в качестве восстановителей твердого углерода, карбида железа и карбида хрома при условии $\alpha=P_{\mathrm{CO}}+P_{\mathrm{CO}_{2}}=1$. $\mathrm{Ha}$ основе анализа термодинамических особенностей восстановления хромита, а также расчета равновесного состава газов в исследованной системе предложены вероятные схемы формирования металлической и карбидной фаз.

3. Выполнено термодинамическое моделирования углеродотермического восстановления хромита железа при различном отношении О/С, а также при введении в систему дополнительных количеств $\mathrm{Fe}_{3} \mathrm{O}_{4}$ и $\mathrm{Cr}_{2} \mathrm{O}_{3}$.

Вместе с тем, без комплексного исследования процесса твердофазного восстановления $\mathrm{Cr}_{2} \mathrm{FeO}_{4}$ практически невозможно установить последовательность фазовых и химических превращений в системе Cr-Fe-C-O, поэтому на следующем 
этапе исследований необходимо оценить кинетические особенности процесса, а также проанализировать закономерности формирования твердых фаз.

\section{ЛИТЕРАТУРА}

1. Гасик М.И. Теория и технология производства ферросплавов / М.И. Гасик, Н.П. Лякишев, Б.И. Емлин. - М.: Металлургия, 1988. - 784 с.

2. Лисняк С.С. Поведение хромитов при нагревании в восстановительной и окислительных газовых средах / С.С. Лисняк, А.М. Беликов, А.Н. Морозов // Огнеупоры. - 1962. - № 9. - С. 417-420.

3. Исследование взаимодействия окислов тугоплавких металлов с углеродом / В.П. Елютин, Ю.А.Павлов, В.П.Поляков, С.Б.Шеболдаев //Физическая химия окислов. М.: Наука, 1971. - С.66-76.

4. Теоретические основы процессов производства углеродистого феррохрома из уральских руд / В.П. Чернобровин, И.Ю. Пашкеев, Г.Г. Михайлов и др. - Челябинск: Изд-во ЮУрГУ, 2004. - 346 с.

5. Исследование восстановления хромита железа углеродом / А.В. Сенин, В.П. Чернобровин, Г.Г. Михайлов и др. // Сталь. - 2004. - № 11. - С. 41-45.

6. Симонов В.К. Термодинамический анализ и особенности механизма твердофазного восстановления Cr2O3 углеродом. Часть 1/ Симонов В.К., Гришин А.М. // Электрометаллургия. - 2012. - №9. - С.21-26.

7. Симонов В.К. Термодинамический анализ и особенности механизма твердофазного восстановления Cr2O3 углеродом. Часть 2/ Симонов В.К., Гришин А.М. // Электрометаллургия. - 2012. - №10. - С.13-18.

8. Рощин В.Е. Механизм и последовательность восстановления металлов в решетке хромшпинелида / В.Е. Рощин, А.В. Рощин, К.Т. Ахметов // Металлы. - 2014. - №2. C. 3-10.

9. Кадарметов Х.Н. О восстановлении хромовых руд / Х.Н. Кадарметов // Восстановительные процессы в производстве ферросплавов. - М.: Наука, 1977. C. $148-151$.

10. Жакибеков Т.Б. Роль газофазного восстановления при электротермии высокоуглеродистого феррохрома / Т.Б. Жакибеков, Т.Д. Такенов // Проблемы научнотехнического прогресса электротермии неорганических материалов: сб. тез. докл. научно-техн. конф. - Днепропетровск: ДМетИ, 1989. - С. 57.

11. Разработка технологических основ энергосберегающего процесса получения хромистых лигатур в твердом состоянии с использованием техногенных отходов промышленных предприятий Украины // Отчет по НИР. - Днепропетровск: ГМетАУ, 1997. - 24c.

12. Теорія металургійних процесів / В.Б. Охотський, О.Л. Костьолов, В.К. Симонов та ін. - К.: ІЗМH, 1997. - 512 с.

13. Условия интенсификации карботермического восстановления хромитов / В.П. Чернобровин, А.В. Сенин, Г.Г. Михайлов, И.Ю. Пашкеев// Вестник Южно- 
Уральского государственного университета. Серия: Металлургия. - 2005. - №3. C. 28-35.

14. Гудремон Э. Специальные стали / Э. Гудремон. - М.: Металлургия, 1966. - Т. 1. 736 c.

15. Циммерман Р. Металлургия и материаловедение : справочник / Р. Циммерман, К. Гюнтер. - М.: Металлургия, 1982. - 480 с.

16. Коняева М. А. Электронная структура, магнитные свойства и стабильность бинарных и тройных карбидов (Fe,Cr)3C и (Fe,Cr)7C3 /M. А. Коняева, Н. И. Медведева // Физика твердого тела. - 2009. - Т. 51, вып. 10. - С. 1965-1969.

17. Кинетика комбинированного восстановления оксидных систем $\mathrm{Fe}-\mathrm{Cr}$ и $\mathrm{Fe}-\mathrm{Cr}-\mathrm{Ni} /$ А.А. Попов, П.Н. Острик, А.Н. Попов и др. // Известия вузов. Черная металлургия. 1987. -№8. - C. 1-4.

18. Острик П.Н. Металлургия губчатых и порошковых лигатур / Острик П.Н., Гасик М.М., Пирог В.Д. - К.: Техніка, 1992. - 128 с.

\section{REFERENCES}

1. Gasik M.I. Teoriya i tehnologiya proizvodstva ferrosplavov / M.I. Gasik, N.P. Lyakishev, B.I. Emlin. - M.: Metallurgiya, 1988. - 784 p. (in russia)

2. Lisnyak S. S. Povedenie hromitov pri nagrevanii v vosstanovitelnoy i okislitelnyih gazovyih sredah / S.S. Lisnyak, A.M. Belikov, A.N. Morozov // Ogneuporyi. -1962. -№ 9. P. 417-420. (in russia)

3. Intensifikatsiya karbotermicheskogo vosstanovleniya hromitov / V.P. Chernobrovin, I.Yu. Pashkeev, V.B. Shmyiga, G.G. i dr. // Ferrosplavyi: Teoriya i tehnologiya proizvodstva: Yubileynyiy sbornik trudov. Chelyabinsk: Izd. YuUrGU, 2001. - 222 p. (in russia)

4. Teoreticheskie osnovyi protsessov proizvodstva uglerodistogo ferrohroma iz uralskih rud / V.P. Chernobrovin, I.Yu. Pashkeev, G.G. Mihaylov i dr. - Chelyabinsk: Izd-vo YuUrGU, 2004. -346 p. (in russia)

5. Issledovanie vosstanovleniya hromita zheleza uglerodom / A.V. Senin, V.P. Chernobrovin, G.G. Mihaylov i dr. // Stal. - 2004. - № 11. - P. 41-45. (in russia)

6. Simonov V.K. Termodinamicheskiy analiz i osobennosti mehanizma tverdofaznogo vosstanovleniya $\mathrm{Cr}_{2} \mathrm{O}_{3}$ uglerodom. Chast1/ Simonov V.K., Grishin A.M.// ElektroMetallurgiya. - 2012. - №9. - P.21-26. (in russia)

7. Simonov V.K. Termodinamicheskiy analiz i osobennosti mehanizma tverdofaznogo vosstanovleniya $\mathrm{Cr}_{2} \mathrm{O}_{3}$ uglerodom. Chast2/ Simonov V.K., Grishin A.M. // ElektroMetallurgiya. - 2012. - №10. - P.13-18. (in russia)

8. Roschin V.E. Mehanizm i posledovatelnost vosstanovleniya metallov $\mathrm{v}$ reshetke hromshpinelida / V.E. Roschin, A.V. Roschin, K.T. Ahmetov // Metallyi. - 2014. - №2. P. 3-10. (in russia)

9. Kadarmetov H.N. O vosstanovlenii hromovyih rud / H.N. Kadarmetov // Vosstanovitelnyie protsessyi v proizvodstve ferrosplavov. - M.: Nauka, 1977. - P. 148-151. (in russia)

10. Zhakibekov T.B. Rol gazofaznogo vosstanovleniya pri elektrotermii vyisokouglerodistogo ferrohroma / T.B. Zhakibekov, T.D. Takenov // Problemyi nauchno-tehnicheskogo progressa 
elektrotermii neorganicheskih materialov: sb. tez. dokl. nauchno-tehn. konf. Dnepropetrovsk: DMetI, 1989. - P. 57. (in russia)

11. Razrabotka tehnologicheskih osnov energosberegayuschego protsessa polucheniya hromistyih ligatur $\mathrm{v}$ tverdom sostoyanii $\mathrm{s}$ ispolzovaniem tehnogennyih othodov promyishlennyih predpriyatiy Ukrainyi // Otchet po NIR. - Dnepropetrovsk: GMetAU, 1997. - 24p. (in russia)

12. Teoriia metalurhiinykh protsesiv / V.B. Okhotskyi, O.L. Kostolov, V.K. Symonov ta in. K.: IZMN, 1997. - 512 p. (in ukrain)

13. Usloviya intensifikatsii karbotermicheskogo vosstanovleniya hromitov / V.P. Chernobrovin, A.V. Senin, G.G. Mihaylov, I.Yu. Pashkeev// Vestnik Yuzhno-Uralskogo gosudarstvennogo universiteta. Seriya: Metallurgiya. - 2005. - №3. - P. 28-35. (in russia)

14. Gudremon E. Spetsialnyie stali / E. Gudremon. - M.: Metallurgiya, 1966. - T. 1. -736 p. (in russia)

15. Tsimmerman R. Metallurgiya i materialovedenie : spravochnik / R. Tsimmerman, K. Gyunter. - M.: Metallurgiya, 1982. - 480 p. (in russia)

16. Konyaeva M. A. Elektronnaya struktura, magnitnyie svoystva i stabilnost binarnyih i troynyih karbidov $(\mathrm{Fe}, \mathrm{Cr})_{3} \mathrm{C}$ i $(\mathrm{Fe}, \mathrm{Cr})_{7} \mathrm{C}_{3} / \mathrm{M}$. A. Konyaeva, N. I. Medvedeva // Fizika tverdogo tela. - 2009. - T. 51, vyip. 10. - P. 1965-1969. (in russia)

17. Kinetika kombinirovannogo vosstanovleniya oksidnyih sistem $\mathrm{Fe}-\mathrm{Cr}$ i $\mathrm{Fe}-\mathrm{Cr}-\mathrm{Ni} /$ A.A. Popov, P.N. Ostrik, A.N. Popov i dr. // Izvestiya vuzov. Chernaya metallurgiya. - 1987. №8. - P. 1-4. (in russia)

18. Ostrik P.N. Metallurgiya gubchatyih i poroshkovyih ligatur / Ostrik P.N., Gasik M.M., Pirog V.D. - K.: TehnIka, 1992. - 128 p. (in russia)

Received 15.01.19

\section{THERMODYNAMIC MODELING OF CARBON-THERMAL REDUCTION OF IRON CHROMITE}

Analysis of the literature data about conditions and mechanism of the reactions of solid-phase reduction of iron chromite has shown that so far there is no single understanding of both the process mechanism and its physicochemical regularities. The complexity of the thermodynamic analysis of such a process lies in its multivariance. Depending on the process conditions, the final reduction products may have different phase and chemical composition.

The purpose of this work is a thermodynamic analysis of iron chromite reduction by carbon at temperatures that preclude the appearance of liquid phases.

A thermodynamic analysis of the main reactions in the $\mathrm{Cr}-\mathrm{O}-\mathrm{C}$ and $\mathrm{Cr}-\mathrm{Fe}-\mathrm{O}-\mathrm{C}$ systems, occurring with the formation of metal and carbide phases of different composition, was performed. The obtained data allow us to predict phase transformations during the reduction of $\mathrm{Cr} 2 \mathrm{FeO} 4$ with carbon from a thermodynamic point of view. The temperatures of the $\mathrm{Cr} 2 \mathrm{FeO} 4$ reduction starting were determined under the conditions for the formation of a metal product and carbides when solid carbon, iron carbide and chromium carbide are used as reducing agents. The hypothesis of the sequence of iron and chromium reduction from chromite at temperatures precluding the appearance of liquid phases was confirmed. A probable scheme for the formation of metal and carbide phases is proposed. Thermodynamic 
modeling of the carbon-thermal reduction of iron chromite was performed at different $\mathrm{O} / \mathrm{C}$ ratios, as well as with the addition of $\mathrm{Fe} 3 \mathrm{O} 4$ and $\mathrm{Cr} 2 \mathrm{O} 3$ to the system. With the constant $\mathrm{Cr} / \mathrm{Fe}$ ratio and temperature, it is the $\mathrm{O} / \mathrm{C}$ ratio that determines the phase composition of the product. Thus, thermodynamic conditions of carbon-thermal reduction of $\mathrm{Cr} 2 \mathrm{FeO} 4$ can be determined to obtain a low carbon ligature.

At the same time, without a comprehensive study of solid phase reduction process of $\mathrm{Cr} 2 \mathrm{FeO} 4$, it is almost impossible to establish a sequence of phase and chemical transformations in the $\mathrm{Cr}-\mathrm{Fe}-\mathrm{C}-\mathrm{O}$ system; therefore, it is necessary to study the kinetic features of the process and also analyze the patterns of solid phase formation.

Keywords: iron chromite, reduction, carbides, carbon, thermodynamic modeling.

\section{ТЕРМОДИНАМІЧНЕ МОДЕЛЮВАННЯ ВУГЛЕЦЕВОТЕРМІЧНОГО ВІДНОВЛЕННЯ ХРОМІТУ ЗАЛІЗА}

В роботі розглянуті термодинамічні особливості твердофазного відновлення хроміту заліза вуглецем. Запропоновані можливі фізико-хімічні схеми формування твердих фаз під час процесу. Розраховані температури початку процесу відновлення хроміту за участю як вуглецю, так і карбідів хрому та заліза. Виконано моделювання розвитку процесу в умовах додаткового введення в систему оксидів заліза та хрому. Показана можливість отримання лігатур комплексного складу на основі хрому в умовах температур, які виключають появу розплаву.

Ключові слова: хромит заліза, відновлення, карбіди, вуглець, термодинамічне моделювання.

Гришин Олександр Михайлович - кандидат техничних наук, доцент кафедри теорії металургійних процесів та хімії НМетАУ, м. Дніпро, Україна.

Grishin Alexander Mikhailovich - candidate of technical sciences, associate professor of the department of theory of metallurgical processes and chemistry, NMetAU, Dnipro, Ukraine.

Надточій Анжела Анатоліївна - кандидат техничних наук, доцент кафедри теорії металургійних процесів та хімії НМетАУ, м. Дніпро, Україна.

Nadtochij Angela Anatolyevna - candidate of technical sciences, associate professor of the department of theory of metallurgical processes and chemistry, NMetAU, Dnipro, Ukraine.

Щеглова Ірина Сергіївна - кандидат хімічних наук, доцент кафедри теорії металургійних процесів та хімії НМетАУ, м. Дніпро, Україна.

Shcheglova Iryna Sergeevna - candidate of chemical sciences, associate professor of the department of theory of metallurgical processes and chemistry, NMetAU, Dnipro, Ukraine. 